A - preparing concepts

$\mathrm{B}$ - formulating methods

$\mathrm{C}$ - conducting research

$\mathrm{D}$ - processing results

E - interpretation and conclusions

$\mathrm{F}$ - editing the final version

\section{The effects of differences in sleep quality and quantity on $\mathrm{VO}_{2 \max }$ levels}

\author{
Nia Sri Ramania ${ }^{A-C}$ iD, Tommy Apriantono Tommy ${ }^{\mathrm{C}, \mathrm{E}-\mathrm{F}}$ (iD, \\ Bagus Winata Bagus*D,F iD
}

Institut Teknologi Bandung

*Correspondence: Bagus Winata Bagus; Institut Teknologi Bandung; email: fransiskusasisibaguswinata@gmail.com

\begin{abstract}
Introduction: Sleep quality and quantity are factors that affect one's cardiorespiratory fitness (CRF). Therefore, this study aims to compare the effects of different sleep quality and quantity on $\mathrm{VO}_{2 \max }$ levels.

Material and methods: 64 participants were involved in this study, and they were divided into two groups based on their sleep quality and quantity. This division was determined by employing sleep pattern questionnaires. Group 1 was comprised of 32 participants with good sleep quality. Generally, they only slept for 6 hours, however, their sleep quality was very good. On the contrary, group 2 consisted of 32 participants with poor sleep quality, irrespective of the fact that their sleep durations were around 7 hours, which is longer than group 1. All participants went through a series of pretest sessions for one week to determine their average heart rate (HR) before and after sleep. Furthermore, they underwent experimental sessions which required them to participate in the cooper $2.4 \mathrm{~km}$ test to determine their $\mathrm{VO}_{2 \max }$ levels.

Results: The results show a significant difference in participants' $\mathrm{VO}_{2 \max }$ levels, with the average in group 1 being higher than in group $2(\mathrm{~F}=5.853)(\mathrm{p}=0.018)$. This result was obtained from statistical tests using a one-way ANOVA.

Conclusions: This study indicates that having good quality sleep for 6 hours plays a crucial role in maintaining and increasing CRF.
\end{abstract}

Keywords: recovery, student, exercise training, training load, recreational sport

\section{Introduction}

Cardiorespiratory fitness (CRF) is an essential part of physical fitness which can be used to predict both levels of fitness and the risk of contracting diseases [1]. In an observational study carried out from 1978 to 2002 using 31,818 male and 10,555 female respondents, Lee et al. [2] concluded that low CRF is a predictor of allcause mortality. Therefore, the study encourages everyone to increase their CRF as a precautionary measure in preventing diseases and reducing the death rate. In short, experts take a direct measurement of maximal oxygen consumption $\left(\mathrm{VO}_{2 \max }\right)$ [3] using various methods, such as simple exercise protocols $[4,5]$ or by employing sophisticated sports equipment in the testing process [6], to determine one's CRF levels. Some previous studies have been conducted to measure the $\mathrm{VO}_{2 \max }$ levels of particular groups based on different variables, namely ethnic differences [7], the demographic location of

This is an Open Access journal, all articles are distributed under the terms of the Creative Commons Attribution-NonCommercial-ShareAlike 4.0 International (CC BY-NC-SA 4.0). License (http://creativecommons. org/licenses/by-nc-sa/4.0/). 
a country [8], types of daily activities [9], and anthropometry differences [10]. These studies were carried out to determine the standard of the $\mathrm{VO}_{2 \max }$ levels in particular groups, which were subsequently used as indicators to analyze the groups' health index [11].

Furthermore, previous studies have shown that physiological and psychological factors such as depression can affect the development of CRF [12]. Moreover, another study also discovered that sleep quality and quantity are two of the factors affecting one's psychology [13]. Based on the above findings, it can easily be concluded that sleep quality and quantity influence cardiorespiratory fitness. This idea is further strengthened by research explaining that sleep is one of the post-exercise recovery (PER) methods performed after carrying out physical activity [14]. This research explains that good sleep quality and quantity can decrease the fatigue index after carrying out exercise.

In this regard, previous studies always focused on the effects of sleep quality and quantity as a recovery method to improve performance $[15,16]$. Fietze et al. [15], for example, measured the sleep quality and quantity of ballet dancers before they carried out their main performance for 67 days using several measurement parameters such as the Epworth Sleepiness Score (ESS) and the Pittsburgh Sleep Quality Index (PSQI). Fietze et al. concluded that sleep quantity and daytime naps can help maintain and improve performance during the training process.

Studies have not been carried out to explore the effects of differences in sleep quality and quantity on one's CRF levels. Therefore, essential to carry out such a study to provide answers to the following question: "between sleep quality and quantity, which is more important in the process of developing one's CRF?" This study compared the sleep quality and quantity toward the $\mathrm{VO}_{2 \max }$ levels and concluded that sleep quality has a more crucial role than the quantity in influencing one's $\mathrm{VO}_{2 \max }$ levels.

\section{Materials and methods}

\section{Participants}

Participants involved in this study were first-year students from the Bandung Institute of Technology. They were invited to participate via the internet and social media by filling out screening data and sleep pattern questionnaires distributed via Google Forms from January 26th to February 1st, 2020, and assessed using the Consensus Sleep Diary proposed by Carney et al. [17]. On February 2nd, 2020, there were a total of 200 registered participants, however, only those that met the inclusion criteria were allowed to participate in the study. The students that met the inclusion criteria were first-year male students registered at ITB, between 18-19 years old, not athletes, and carrying out sporting or exercising activities at least once a week with a minimum duration of 15 minutes. Furthermore, the inclusion criteria included no history of musculoskeletal injuries in the past three months, nor cardiovascular disease, smoking, mental or physical impairments, or any previous or current intake of psychoactive substances. Participants also had a sleep duration of at least 6 hours per night, according to the recommendations of previous studies conducted by Pagel et al. [18].

In this study, specifically 136 participants were included in the exclusion criteria, namely having a sleep duration of less than 6 hours $(\mathrm{n}=31)$, asthma $(\mathrm{n}=18)$, a history of mental illness $(\mathrm{n}=16)$, a history as an athlete $(n=37)$, or a history of cardiovascular disease $(n=34)$. After selecting the inclusion and exclusion criteria in this study, the participants were selected $(n=64)$. Later they were gathered to receive explanations regarding the procedures and risks in this study. After all the participants had received the explanation they were asked to fill out and sign the informed consent form. The ethics committee approved all procedures of the POLTEKKES Bandung (04/KEPK/PE/XX/2019) with the research design shown in Figure 1.

\section{Questionnaires}

The questionnaires aimed to determine which participants met the inclusion criteria and the right groups for the participants. The questions were: (1) What is your gender? (2) How old are you? (3) Are you an athlete? If not, do you like to participate in sport/exercise? How long do you exercise for each week? (4) Do you have a history of musculoskeletal injuries in the past three months? (5) Do you have a history of cardiovascular disease? (6) Do you currently smoke or have a history of smoking? (7) Do you have a history of mental illness or psychological disorders?

To determine participants' sleep quality and quantity, this study used a summary of questionnaires in accordance with the following protocols: (1) What time do you try to go to sleep? (2) What time do you start sleeping? (3) What time do you wake up? (4) What time do you get out of bed? (5) How long do you sleep for? (6) What is the level of your sleep quality? (self-reported sleep quality on a 4-point Likert-type scale, where 1 is considered to be very good and 4 is considered to be poor) (7) If your sleep quality is 3 or 4, please comment on what makes your sleep quality poor?

\section{Procedure}

All participants were gathered to take part in a familiarization session. This session aimed to classify their sleep patterns based on their quantity and quality of 


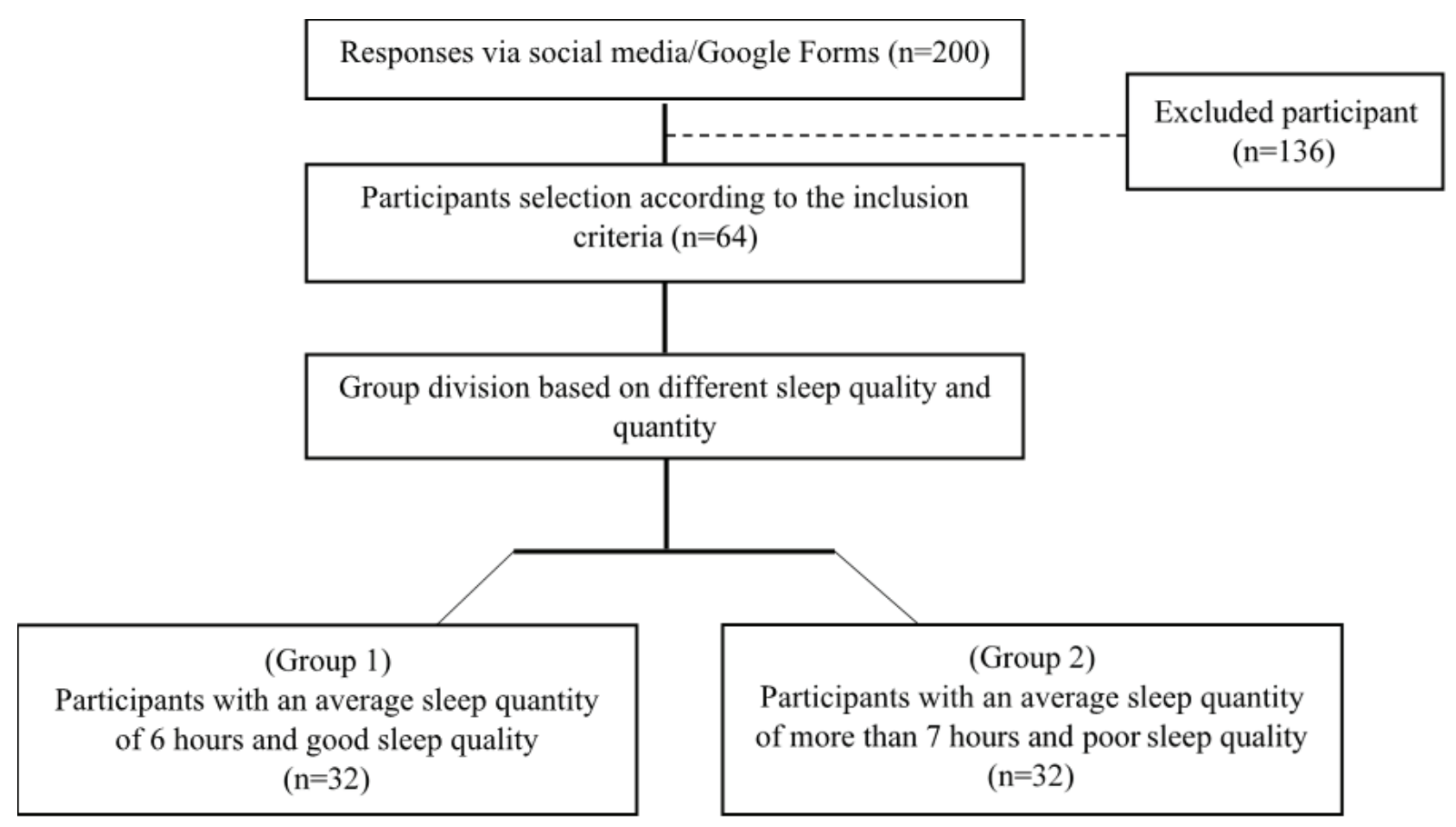

Fig. 1. Research designs

sleep and to explain Cooper's $2.4 \mathrm{~km}$ run test. This session lasted for a week before the test session began. In order to ascertain the sleep quantity and quality of the selected participants, this study required them to wear an accelerometer (Actigraph) worn on the right wrist for 6 nights. The raw accelerometer data were converted to sleep parameters using the actilife software from the accelerometer. According to the built-in Sadeh scoring algorithm, when plotted on an actigraph, any movement is considered to mean that the subject is "awake" [19]. In actigraphic measurements, several results can be used as a reference in the process of classification into 2 different groups. The results obtained are (1) sleep latency, which is defined as the time between getting into bed and sleep onset; (2) corrected sleep duration, which is defined as the total sleep duration for each participant; (3) sleep efficiency, which is defined as the proportion of actual sleep time during the total time spent in bed.

To determine each participant's sympathovagal balance, a measurement of the average heart rate (HR) as a stress biomarker was carried out in this familiarization session [20]. HR measurement was performed 10 minutes before going to bed and 10 minutes after waking up. All participants wore the Xiaomi Mi Band 4 that is worn on the left wrist. They were required to record and report their HR results to each administrator. Each participant was required to take a photo on their Xiaomi Mi Band 4 screen and notify the administrator as a form of report validation. After the familiarization session, the participants were divided into two groups on the 7th day. Group 1 was comprised of 32 participants with good sleep quality despite sleeping for only 6 hours. On the contrary, group 2 consisted of 32 participants with poor sleep quality despite sleeping for approximately 7 hours, which is longer than in group 1.

The experimental session started on day 8 . This session was divided into 2 measurement sessions, namely the anthropometric and the $\mathrm{VO}_{2 \max }$ measurement sessions. In this session, participants avoided caffeine and alcohol 24 hours before the experimental session started. In the anthropometry test, the participants' body weight and fat percentage were measured using the OMRON HBF-375 Karada Scan Body Composition Scale. The participants were asked to wear minimal clothes without footwear. Their body height was measured using a stadiometer with $0.1 \mathrm{~cm}$ readability (Seca 214 Portable Stadiometer, Cardinal Health, Ohio, USA) in accordance with standardized procedures. Meanwhile, their body mass index was calculated using the following formula: the ratio of the body mass (kilograms) divided by the body height (meters) squared. After the anthropometry test, all participants went through the $\mathrm{VO}_{2 \max }$ test. Cooper's 2.4 run test was employed to provide data regarding participants' maximum $\mathrm{VO}_{2 \max }$ [21]. Meanwhile, their heart rate intensity during the 2.4 run test was monitored using a Polar RS400. The environmental conditions were kept constant at an ambient temperature of $28-30^{\circ} \mathrm{C}$ and relative humidity of $65-75 \%$ over the 2 sessions. During the recovery period, all subjects were allowed to drink mineral water and libitum. 


\section{Statistical analysis}

The values were presented as mean $\pm \mathrm{SD}$ with the normal distribution of the sample examined using the Shapiro-Wilk test. The ANOVA, used as a repeated measurement, was applied for each parameter in groups 1 and 2 , followed by calculating the $95 \%$ confidence intervals $(\mathrm{CI})$ and percentage changes. Finally, the statistical significance was accepted at the level of $p<0.05$ using the SPSS software (V.21.0).

\section{Results}

Table 1 shows the average anthropometry value of all participants based on their groups.

Tab. 1. Anthropometric characteristics of participants

\begin{tabular}{lcc}
\hline Variables & Group 1 & Group 2 \\
& $\bar{x} \pm \mathrm{SD}$ & $\bar{x} \pm \mathrm{SD}$ \\
\hline Age (years) & $18.6 \pm(0.48)$ & $18.6 \pm(0.47)$ \\
Weight $(\mathrm{kg})$ & $70.3 \pm(6.42)$ & $68.31 \pm(5.78)$ \\
Height $(\mathrm{cm})$ & $175.5 \pm(4.96)$ & $173.5 \pm(4.74)$ \\
BMI $\left(\mathrm{kg} / \mathrm{m}^{2}\right)$ & $22.85 \pm(2.25)$ & $22.67 \pm(1.71)$ \\
\hline
\end{tabular}

Table 2 shows the comparison of average HR 10 minutes before and after waking up, the sleep latency, corrected sleep duration, and sleep efficiency in the two groups that were carried out for 6 days in the familiarization session.

Meanwhile, Table 3 shows the average time of the Cooper's test and $\mathrm{VO}_{2 \max }$ of each group, with the results analyzed using the one-way ANOVA.

\section{Average HR and sleep latency, duration, and efficiency}

There was no significant difference in the average peak HR between Group 1 and 2 during Cooper's $2.4 \mathrm{~km}$ test $(\mathrm{p}=0.741)$, as shown in Figure 2 .

In the measurement of average HR, ANOVA showed a significant difference in the average HR 10 minutes after waking up between Group 1 and $2(\mathrm{p}=0.001)$, while there was no significant difference in the average HR before going to sleep in the two groups $(p=0.736)$. These results show that Group 1 had a shorter sleep latency than Group $2(5.5 \pm 0.41$ vs. $7.2 \pm 1.74 ; \mathrm{p}=0.044)$. Meanwhile, ANOVA showed that there were significant differences between the two groups in the measurement of sleep duration $(\mathrm{p}=0.001)$, and sleep efficiency $(\mathrm{p}=0.001)$, respectively.

Tab. 2. Descriptive data on average HR, sleep latency, corrected sleep duration, and sleep efficiency on familiarization session

\begin{tabular}{lccc}
\hline Variables & Group 1 & Group 2 & $p$-value \\
\hline HR-pre $_{1}(\mathrm{bpm})$ & \multicolumn{1}{c}{$\mathrm{s}_{\mathrm{SD}}$} & $68.5 \pm(1.72)$ & 0.736 \\
HR-pre $_{2}(\mathrm{bpm})$ & $66.1 \pm(0.73)$ & $73.2 \pm(1.87)$ & 0.001 \\
Sleep latency (min) $_{\text {Corrected sleep duration (hours) }}$ & $5.5 \pm(0.41)$ & $7.2 \pm(1.74)$ & 0.044 \\
Sleep efficiency (\%) & $6.5 \pm(0.39)$ & $8.2 \pm(0.36)$ & 0.000 \\
\hline
\end{tabular}

HR-pre ${ }_{1}$, average heart rate before sleeping during 6-weeks; HR-pre ${ }_{2}$, average heart rate shortly after waking up during 6-weeks. Statistically significant differences between Group 1 and Group $2(\mathrm{p}<0.05)$.

Tab. 3. Effects of sleep quality and quantity toward the $\mathrm{VO}_{2 \max }$

\begin{tabular}{|c|c|c|c|c|}
\hline \multirow{2}{*}{ Variables } & Group 1 & Group 2 & \multirow{2}{*}{ F value } & \multirow{2}{*}{$\begin{array}{l}\text { ANOVA } \\
p \text {-values }^{(\mathrm{a})}\end{array}$} \\
\hline & $\bar{x} \pm \mathrm{SD}$ & $\bar{x} \pm \mathrm{SD}$ & & \\
\hline Cooper test time (min) & $13.99 \pm 2.47$ & $15.42 \pm 3.02$ & 4.945 & $0.030^{*}$ \\
\hline $\mathrm{VO}_{2 \max }\left(\mathrm{ml} / \mathrm{kg} / \mathrm{min}^{-1}\right)$ & $35.44 \pm 5.78$ & $30.03 \pm 6.10$ & 5.853 & $0.018^{*}$ \\
\hline
\end{tabular}

* Statistically significant differences between Group 1 and Group $2(\mathrm{p}<0.05)$. 


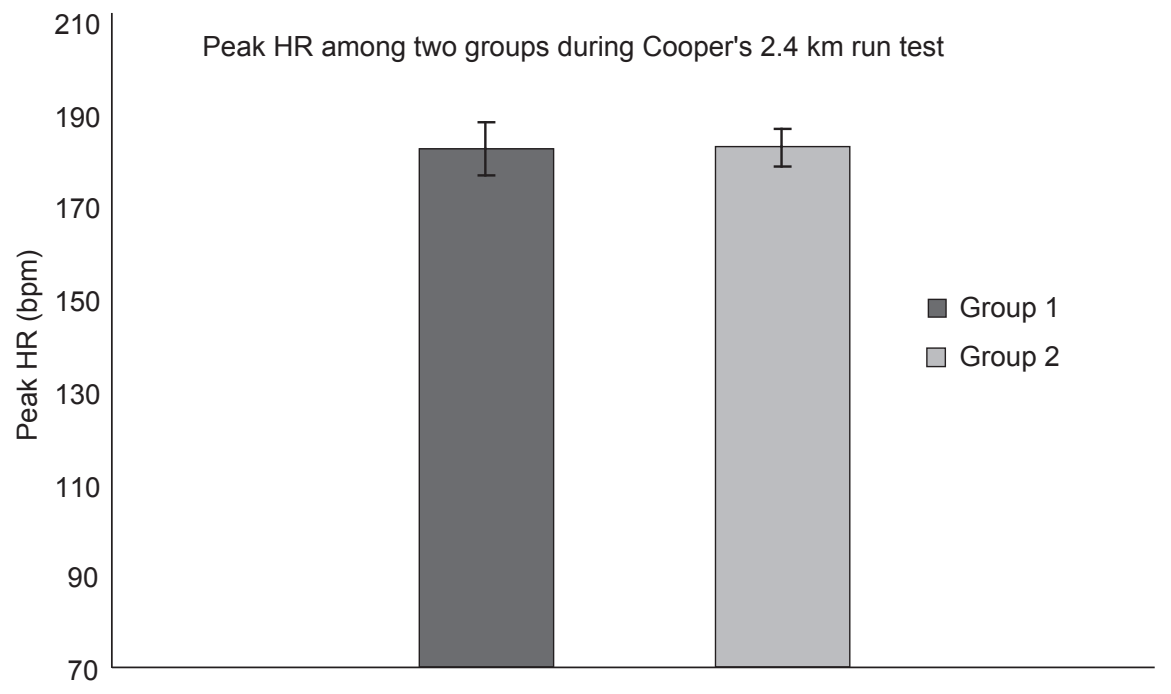

Fig. 2. Peak HR among Group 1 and Group 2 during the cooper $2.4 \mathrm{~km}$ test

\section{Cooper time and $\mathrm{VO}_{2 \max }$}

Based on statistical tests using the one-way ANO$\mathrm{VA}$, the results show some significant differences in the Cooper's test time of groups 1 and $2(\mathrm{~F}=4.945)$ $(\mathrm{p}=0.030)$. Group 1 had an average of Cooper's test time that was faster than Group 2. Furthermore, the $\mathrm{VO}_{2 \max }$ results obtained through the Cooper's test time conversion show that Group 1 had an average $\mathrm{VO}_{2 \max }$ higher than Group $2(\mathrm{~F}=5.853)(\mathrm{p}=0.018)$.

\section{Discussion}

The objective of this study is to compare the effects of sleep quality and quantity on $\mathrm{VO}_{2 \max }$ levels. Therefore, based on the results, the authors have concluded that an average night sleep of 6 hours with good quality can maintain and develop one's $\mathrm{VO}_{2 \max }$, compared to sleeping for more than 7 hours with poor quality. These results are important due to their ability to answer the following questions: "Which one is more important between sleep quality and quantity in CRF development?" Finally, this study asserted that sleep quality plays a more crucial role in CRF development than quantity. However, sleep quality needs to be followed with the quantity standard set by primary care sleep medicine [17], which is a minimum of six hours a day for adults.

In this study, it was shown that Group 1 had a significant difference in average HR 10 minutes after waking up $(\mathrm{p}=0.001)$, where Group 1 had a lower average HR $(66.1 \pm 1.74 \mathrm{bpm})$ than Group $2(73.2 \pm 1.87)$. On the other hand, Group 1 had better sleep quality than Group 2. This is indicated through a greater sleep efficiency $(90.5 \pm 1.26 \%$ vs. $79.8 \pm 5.19 \%)$. Based on these findings, this study supports previous studies that the quality and quantity of sleep affects a person's HR. This is because HR can be used as a stress biomarker. More specifically, the study conducted by Michels et al. [22] concluded that sleep quality is related to an unhealthy heart rate variability outcome, as well as increased stress. In his explanation, sleep quality that causes the percentage of sleep efficiency to be shorter can increase sympathetic activity through higher levels of the catecholamines norepinephrine and epinephrine through activation of the stress system.

The main results in these findings also show that Group 1 had a greater $\mathrm{VO}_{2 \max }$ than Group 2. Although the authors have had difficulties in getting supporting references, the previous statement based on the literature stating that sleep quality and quantity affect cardiovascular function can be used as the basis for supporting this finding $[23,24]$. This is very reasonable considering that $\mathrm{VO}_{2 \max }$ is a parameter for measuring cardiorespiratory fitness (CRF) that can be an independent predictor for an array of health outcomes, especially in knowing one's cardiorespiratory function [24]. Through this finding, this study has clearly proven that good sleep quality with an average sleep efficiency of $90.5 \pm 1.26 \%$ affects cardiorespiratory function, causing higher $\mathrm{VO}_{2 \max }$ results than the average sleep efficiency of $79.8 \pm 5.19 \%$.

Hausswirth et al. [25] carried out research to determine the sleep quality of twenty-seven trained male triathletes that performed overload and normal training sessions for 6 weeks. These observations were conducted using a wristwatch actigraphy and concluded that sleep disturbance, which causes poor quality sleep, can disrupt the planned exercise program, thereby increasing overreaching functional problems during highvolume training. 
Another important finding of this study regards the causes of sleep quality disturbance. The research found that $80 \%$ of participants that experience poor sleep quality share the same opinion that the disturbance comes from anxious feelings due to unfinished assignments. This is quite reasonable because the number of assignments given by lecturers to the first-year students of ITB is numerous, thereby leading to a feeling of anxiety.

The above finding regarding students' anxiety due to various assignments that lead to poor sleep quality is in line with a study carried out by Ayala et al. [26]. Ayala examined the sleep quality and quantity of medical students in the US and realized that the first - and second-year students experienced worse sleep quality and quantity than the third- and fourth-year students. This study indicates that the number of assignments influences students' sleep quality and quantity. Furthermore, the study also reveals that third- and fourth-year students tend to be more relaxed because their assignments are fewer as they need to be more focused on their thesis. On the contrary, first- and second-year students tend to be more stressed as they still have numerous assignments assigned by their lecturers.

In addition to the different quantities of assignments, Ayala et al. [26] also stated that psychology plays a significant role in adaptation, which in turn affected the changes in the sleep quality and quantity of the US medical students. Specifically, the study explains that changes from high school to college learning patterns at US medical universities can affect the psychological adaptation cycles which trigger changes in students' sleep cycles.

Although this study differs from the study conducted by Ayala et al. [26] in terms of the types of participants and the university's character, there are some similarities, such as the numerous assignments that burden participants, and the role of psychological adaptation, which changes learning patterns from high school to college. These aspects can possibly lead to negative changes in students' sleep quality and quantity.

Finally, this study encourages all students to pay more attention to and preserve discipline in maintaining good sleep patterns qualitatively and quantitatively. This is important because the results of this study show that an average night's sleep of 6 hours of good quality can maintain and develop one's $\mathrm{VO}_{2 \max }$, compared to sleeping for more than 7 hours with poor quality. Furthermore, some limitations are associated with this stu$\mathrm{dy}$, such as the influence of the participants' lifestyles and backgrounds in conducting sport/exercise, which could have affected the results. Therefore, irrespective of the fact that the best efforts were used to determine sample criteria that fit the inclusion criteria, further studies are needed to determine the in-depth observations of participants' backgrounds in carrying out sport/exercise. Meanwhile, the second limitation is associated with the need for more samples to reveal more facts.

\section{Conclusion}

In conclusion, this study indicates that sleeping for 6 hours with good quality plays a crucial role in maintaining and developing one's CRF. Practically, the study suggests the need for students to sleep for a minimum of 6 hours daily by paying attention to various psychological or other external factors that can affect their sleep quality.

\section{Funding}

This research received no external funding.

\section{Conflicts of interest}

The authors declare no conflict of interest.

\section{Acknowledgments}

The authors are grateful to the Bandung Institute of Technology, specifically to the Department of Sport Science, for their assistance in carrying out this study. This study was not financially supported by any individual, organization, or firm.

\section{References}

1. Sloan RA, Haaland BA, Leung C, Padmanabhan U, Koh HC, Zee A. Cross-validation of a non-exercise measure for cardiorespiratory fitness in Singaporean adults. Singapore Med J. 2013 Oct; 54(10): 576-80.

2. Lee DC, Sui X, Ortega FB, Kim YS, Chruch TS, Winett RA, et al. Comparisons of leisure-time physical activity and cardiorespiratory fitness as predictors of all-cause mortality in men and women. Br J Sports Med. 2011 May; 45(6): 504-10.

3. Kaminsky LA, Arena R, Myers J. Reference standards for cardiorespiratory fitness measured with cardiopulmonary exercise testing: data from the fitness registry and the importance of exercise national database. Mayo Clin Proc. 2015 Nov; 90(11): 1515-23.

4. Magiera A, Jagodziński A, Kaczmarczyk K, Wiszomirska I. The level of efficiency of adult women in premature based on analysis of power input and power regulation stress test. Adv Rehab. 2016 Jan; 30(1): 5-10.

5. Myers J, Prakash M, Froelicher V, Do D, Partington S, Atwood JE. Exercise capacity and mortality among men referred for exercise testing. N Engl J Med. 2002 Mar; 346(11): 793-801. 
6. Löllgen H, Leyk D. Exercise testing in sports medicine. Dtsch Arztebl Int. 2018 Jun; 115(24): 409-16.

7. Williams CJ, Williams MG, Eynon N, Ashton KJ, Little JP, Wisloff U, et al. Genes to predict $\mathrm{VO}_{2 \max }$ trainability: a systematic review. BMC Genomics. 2017 Nov; 18(Suppl 8): 831.

8. Conn VS, Hafdahl AR, Cooper PS, Brown LM, Lusk SL. Meta-analysis of workplace physical activity interventions. Am J Prev Med. 2009 Oct; 37(4): 330-9.

9. Jurca R, Jackson AS, LaMonte MJ, Morrow Jr JR, Blair SN, Wareham NJ, et al. Assessing cardiorespiratory fitness without performing exercise testing. Am J Prev Med. 2005 Oct; 29(3): 185-93.

10. Espinoza F, Delgado-Floody P, Martínez-Salazar C, Jerez-Mayorga D, Guzmán-Guzmán IP, CaamañoNavarrete F, et al. The influence of cardiometabolic risk factors on cardiorespiratory fitness in volunteer Chilean firefighters. Am J Hum Biol. 2019 Sep; 31(5): e23280.

11. Shenoy S, Tyagi BS, Sandhu JS. Concurrent validity of the non-exercise based $\mathrm{VO}_{2 \max }$ prediction equation using percentage body fat as a variable in Asian Indian adults. Sports Med Arthrosc Rehabil Ther Technol. 2012 Sep; 4(1): 34.

12. Herbsleb M, Schumann A, Lehmann L, Gabriel HHW, Bär KJ. Cardio-respiratory fitness and autonomic function in patients with major depressive disorder. Front Psychiatry. 2020 Feb; 10: 980.

13. Bonnar D, Bartel K, Kakoschke N, Lang C. Sleep interventions designed to improve athletic performance and recovery: a systematic review of current approaches. Sports Med. 2018 Mar; 48(3): 683-703.

14. Samuels C. Sleep, recovery, and performance: the new frontier in high-performance athletics. Phys Med Rehabil Clin N Am. 2009 Feb; 20(1): 149-59.

15. Fietze I, Strauch J, Holzhausen M, Glos M, Theobald $\mathrm{C}$, Lehnkering $\mathrm{H}$, et al. Sleep quality in professional ballet dancers. Chronobiol Int. 2009 Aug; 26(6): 1249-62.
16. Fullagar HH, Skorski S, Duffield R, Hammes D, Coutts AJ, Meyer T. Sleep and athletic performance: The effects of sleep loss on exercise performance, and physiological and cognitive responses to exercise. Sports Med. 2015; 45: 161-86.

17. Carney CE, Buysse DJ, Ancoli-Israel S, Edinger JD, Krystal AD, Lichstein KL, et al. The consensus sleep diary: standardizing prospective sleep self-monitoring. Sleep. 2012 Feb 1; 35(2): 287-302.

18. Pagel J, Pandi-Perumal S. Primary care sleep medicine. Totowa: Humana Press; 2007.

19. Sadeh A. The role and validity of actigraphy in sleep medicine: An update. Sleep Med Rev. 2011; 15: 259-67.

20. Marques AH, Silverman MN, Sternberg EM. Evaluation of stress systems by applying noninvasive methodologies: measurements of neuroimmune biomarkers in the sweat, heart rate variability and salivary cortisol. Neuroimmunomodulation. 2010; 17: 205-8.

21. Burger SC, Bertram SR, Stewart RI. Assessment of the $2.4 \mathrm{~km}$ run as a predictor of aerobic capacity. S Afr Med J. 1990 Sep; 78(6): 327-9.

22. Michels N, Clays E, De Buyzere M, Vanaelst B, De Henauw S, Sioen I. Children's sleep and autonomic function: low sleep quality has an impact on heart rate variability. Sleep. 2013 Dec; 36(12): 1939-46.

23. Knutson KL. Sleep duration and cardiometabolic risk: a review of the epidemiologic evidence. Best Pract Res Clin Endocrinol Metab. 2010; 24: 731-43.

24. Nagai M, Hoshide S, Kario K. Sleep duration as a risk factor for cardiovascular disease-a review of the recent literature. Curr Cardiol Rev. 2010; 6: 54-61.

25. Hausswirth C, Louis J, Aubry A, Bonnet G, Duffield R, LE Meur Y. Evidence of disturbed sleep and increased illness in overreached endurance athletes. Med Sci Sports Exerc. 2014; 46(5): 1036-45.

26. Ayala EE, Berry R, Winseman JS, Mason HR. A crosssectional snapshot of sleep quality and quantity among US medical students. Acad Psychiatry. 2017 Oct; 41(5): 664-8. 